\title{
On the Effect of Ageing on the Erosion of EB-PVD TBCs
}

\author{
R.G Wellman and J.R Nicholls \\ School of Industrial and Manufacturing Science \\ Cranfield University, Bedford, \\ MK 43 OAL, UK.
}

\begin{abstract}
Thermal barrier coatings have been used in gas turbine engines for some four decades, and the erosion resistance of these coatings has been well documented over the years by various different groups. However, as far as can be ascertained most of the laboratory research on erosion resistance of the coatings has been conducted on the coatings in the as-received condition. The effect of service conditions on the erosion rate of the coatings has not been addressed. This paper looks at the effects of thermal aging on the erosion rate of electron beam physical vapour deposited thermal barrier coatings (EB-PVD TBCs) by testing the erosion resistance of coatings that have received various different heat treatments and comparing them to those in the as received condition.
\end{abstract}

Initially two different aging heat treatments were used $1500^{\circ} \mathrm{C}$ for $24 \mathrm{hrs}$, aimed at sintering the ceramic columns, and a less severe aging of $1100^{\circ} \mathrm{C}$ for $100 \mathrm{hrs}$. It was found that both of the heat treatments resulted in a significant increase in the erosion rates when compared to the as received samples. Subsequent to the initial tests, it was found that heat treating the TBC for 30 hours at $1100^{\circ} \mathrm{C}$ resulted in an insignificant increase in the erosion rate. For the samples given the higher temperature heat treatment, the increase in the erosion rate was attributed to the fact that the columns were partially sintering together which enabled cracks to propagate into neighbouring columns, as opposed to stopping at column boundaries as 
occurs in samples that have not been heat treated. This results in an increase in erosion rate due to the fact that more material is removed per impact event.

\section{Introduction}

The erosion of thermal barrier coatings has been well documented for both air plasma sprayed (APS) and electron beam (EB) physical vapour deposited (PVD) thermal barrier coatings (TBCs) [1-8]. Work has also been carried out on the erosion mechanisms[2,9] and on modelling the erosion of EB PVD TBCs[10]. But most of this work has been conducted on coatings in the as received condition. However, one question that has been frequently asked and which has yet to be answered is: How does the erosion rate of an EB-PVD TBC change due to ageing in a gas turbine engine? Recent work by Janos et al[1 1] looked at the effect of thermal aging and porosity levels on the erosion rates of APS TBCs. It was found that both the erosion resistance and the microhardness of the TBCs increased with an increasing aging temperature (for a constant porosity) and decreased with increasing porosity. This increase in hardness and erosion resistance was attributed to the onset of sintering which strengthened the structure of the TBC, particularly the inter-splat cohesion. This paper looks at the effect of ageing and sintering treatments on the room temperature erosion rate of EB PVD TB Cs, thus complimenting the work done by Janos et al [11].

Two different sets of ageing times and temperatures were used on different types of specimens, as listed in Table 1 and 2. The samples were all coated with a standard $\mathrm{ZrO}_{2}-8 \mathrm{wt} \%$ Y2O3, by the EB-PVD technique.

Of the four samples on the alloy substrate two were tested in the as received condition, as reference samples, while the other two were heat treated for 100 hours at $1100^{\circ} \mathrm{C}$ to simulate 
service temperatures, samples 3 and 4. In the second set of tests, EB PVD TBCs were deposited onto alumina and zirconia; one was aged at $1100^{\circ} \mathrm{C}$ for $30 \mathrm{hrs}$, sample 12 , the second was aged at $1100^{\circ} \mathrm{C}$ for $100 \mathrm{hr}$, sample 11 , a third was heat treated at $1500^{\circ} \mathrm{C}$ for 24 and one was kept as a reference sample.

Another aspect that needs to be addressed is the role of sintering, associated with densification of the TBC surface due to the much higher temperatures expected in this region as a result of the thermal gradient across the coating in service, and to what degree it will affect erosion rates. To this end, initially four samples were coated with a standard EB PVD PSZ. Two were alumina substrates and two were zirconia substrates and these were then heat treated for 24 hrs at $1500^{\circ} \mathrm{C}$, in order to ensure sintering of the columns at the sample surface. After the heat treatment these samples were found to have bowed significantly with the TBC on the concave side in all cases, as illustrated in Figure 1. As this was not expected, it was decided to subject uncoated, otherwise identical, alumina and zirconia tiles to the same heat treatment. The uncoated samples came out of the heat treatment without curvature indicating that the curvature must be due to an interaction between the coating and substrate arising from the sintering process.

The radius of curvature, of four of the samples that were heat treated for $24 \mathrm{hrs}$ at $1500^{\circ} \mathrm{C}$, was measured using a Dektak3 ST surface profilometer the results of which are given in Table 3 . Each sample was measured in two orthogonal directions, and as can be seen from the results and the micrograph, Figure 1, the alumina sample, on the right, has a significantly smaller radius of curvature than the zirconia sample.

These results show that during the $1500^{\circ} \mathrm{C} / 24 \mathrm{~h}$ anneal significant lateral shrinkage of the EB PVD TBC has occurred. On cooling to room temperature this has lead to a net tensile stress 
in the coating (and associated compressive stresses in the substrate) resulting in the observed concave sample geometry. Differences in the expansion coefficients of the alumina and zirconia substrates account for the observed differences in the degree of curvature. Crack opening due to sintering is predominantly in one direction, as can be seen in Figure 11, it is believed that this accounts for the difference in the radius of curvature in the two orthogonal directions.

\section{The Test Rig and Erosion Test Procedure}

The erosion tests were all carried out in the high temperature erosion facility at Cranfield University a schematic of which is given in Figure 2. The rig consists of a number of key components starting with the compressor $(\mathrm{C})$, which supplies a pressure vessel $(\mathrm{P})$. This is there to ensure that a constant pressure of compressed air is supplied to the heating system $(\mathrm{H})$. The air passes through a convoluted, labyrinth path in the pressurised heating system, which is electrically heated, before entering the acceleration tube $(\mathrm{T})$. The erodent material is fed via a screw feeder and a venturii nozzle into the acceleration tube, where the compressed air accelerates the particles before they impact the test specimen in the chamber $(\mathrm{S})$. The test samples are attached to a carousel, which is capable of holding six different specimens at different angles with respect to the impacting particle stream.

The range of operating conditions possible are given in Table 4, where it should be noted that the maximum velocity of the erodent is dependent on the particle size and its density. Small, low density particles are capable of the highest velocities and almost attain the gas velocity.

All samples were weighed before the erosion testing and then placed in the carousel. Each sample was then exposed to the particle laden gas stream for 30s after which, and once all the 
samples had been tested, they were removed from the rig and re-weighted. This was repeated for six exposure periods or until coating penetration. For this particular set of tests the following erosion conditions were used, Table 5.

\section{Results}

Unfortunately, not all the samples could be tested as originally planned. One of the alumina tiles cracked while measuring the radius of curvature and then broke during the X-Ray analyses. The second alumina sample broke during the first erosion increment, before any mass change could be determined, thus there is no erosion rate data for the sintered TBC deposited on alumina tiles in the first set of tests. Further, one of the coatings on the C263 substrate spalled during the aging process so only one aged sample was erosion tested. Thus only 5 samples were tested the results of which are presented graphically in Figure 3 with measured erosion rates summarised in Table 6.

The results of the second set of samples are presented graphically in Figure 4, as mentioned earlier sample $10\left(24 \mathrm{hrs} @ 1500^{\circ} \mathrm{C}\right)$ spalled during the second erosion increment, and presented in Table 7.

In Tables 6 and 7 the total erosion rate is calculated from the total mass change divided by the total mass erodent, where as the steady-state erosion rate is calculated for the straight line section of the erosion graph; see Figures 3 and 4 . Both of the sintered samples $\left(1500^{\circ} \mathrm{C}\right.$ for 24hrs) on the zirconia tile had almost eroded through after 5 increments, but initially showed a significant incubation period. The other samples, as received and aged at $1100^{\circ} \mathrm{C}$ for $100 \mathrm{hrs}$, attained a steady state erosion rate almost immediately. 
The bar chart, Figure 5, shows how erosion rate increases with an increase in the aging condition. Aging for $30 \mathrm{hrs} @ 1100^{\circ} \mathrm{C}$ results in a small increase in the erosion rate $(20 \%)$, while 100hrs @ $1100^{\circ} \mathrm{C}$ almost doubles the erosion rate and $24 \mathrm{hrs} @ 1500^{\circ} \mathrm{C}$ results in a four fold increase in the erosion rate.

\section{X-Ray Analysis}

In order to investigate whether there were any phase transformations occurring during the aging treatments, X-ray diffraction analysis was performed on a number of the samples in the as received condition, and then again on the same samples after heat treatment. The X-ray diffraction analysis on the C263 substrate in the as-received condition showed that the coating was tetragonal and with a crystal orientation of (200) for the ceramic deposited on the C263 aluminised material. While the ceramic deposited on the alumina tiles had a predominantly (311) crystal orientation, as illustrated in Figure 6.

Figure 7 shows that there is no change in the crystallographic nature of the YSZ after $100 \mathrm{hrs}$ at $1100^{\circ} \mathrm{C}$. However, this is not the case for the sample heat treated for $24 \mathrm{hrs}$ at $1500^{\circ} \mathrm{C}$, illustrated in Figure 8, where there has been a significant change in the crystal structure of the YSZ. The results presented here are for the ceramic deposited on the alumina substrate under the various heat treatment conditions. Similar observations were observed for the ceramic deposited on the zirconia substrate in the as received and the $1500^{\circ} \mathrm{C} / 24 \mathrm{~h}$ condition.

\section{Discussion}

It is interesting to note that all three of the reference samples had very similar erosion rates (all within one standard deviation) while there was a large scatter in the aged and sintered 
erosion rates. The samples were coated in different runs and one reference sample was tested for each of the coating runs to track repeatability. The results from the reference samples indicate that there is a high degree of reproducibility in both the erosion testing and coating production. This then implies that the large scatter in the results from the heat treated samples must arise from the heat treatment.

As can be seen from the micrographs, Figures 9 through to Figure 11, the sample that was aged at $1500^{\circ} \mathrm{C}$ for $24 \mathrm{hrs} \mathrm{had} \mathrm{started} \mathrm{to} \mathrm{sinter} \mathrm{resulting} \mathrm{in} \mathrm{an} \mathrm{overall} \mathrm{larger} \mathrm{apparent} \mathrm{column} \mathrm{diameter}$ with more open boundaries when compared to the sample in the as received condition. It should also be noted that the pyramidal tops, which are a distinctive feature of EB PVD TBCs, were no longer evident after sintering at $1500^{\circ} \mathrm{C}$. The sample that was aged for $100 \mathrm{hrs}$ at $1100^{\circ} \mathrm{C}$ showed no obvious signs of sintering, or any visible changes to the microstructure as a result of the heat treatment.

After erosion testing each sample was sectioned, mounted in resin, polished and examined in the scanning electron microscope (SEM). In figure 12, cross-sections of the as received and the sintered TBCs are compared. For the as received sample the pyramidal tops as well as the dendritic microstructure of the TBC are clearly visible. This is not the case for the sintered sample where one may observe that there is also some evidence of the columns sintering together. This is better illustrated in Figure 13, where sintering between the columns can be clearly seen.

As can be seen by comparing the micrographs in Figure 13 (a) and Figure 14 (a) and (b), there is no evidence for a change in the erosion as a result of these aging treatments. These micrographs are consistent with the published mechanism for small particle erosion, namely near surface cracking of the TBC columns $[9,10]$. This implies that any changes in the 
erosion rate must be due to structural changes, as a result of sintering and phase transformations and/or changes in the mechanical properties, fracture toughness and hardness, of the TBC due to the thermal aging processes.

In the case of the $1500^{\circ} \mathrm{C}$ aged samples the increase in the erosion rate was attributed to the fact that the columns sintered together allowing cracks initiated in the near surface region to propagate further resulting in a greater volume loss per impact and hence a greater erosion rate.

The samples heat treated at $1100^{\circ} \mathrm{C}$ for various times showed no signs of sintering, yet still showed a significant increase in the erosion rate compared to the as received samples, which implies that other factors also affect the erosion rate. This is most likely due to changes in the mechanical properties of the TBC due to the aging process, in the form of changes in the microporosity of the columns. Due to the columnar microstructure of EB PVD TBCs it is not easy to measure the mechanical properties of the coating. An in depth study on how the aging treatments affect the hardness and the fracture toughness of the columns needs to be undertaken in order to fully understand this increase in the erosion rate.

\section{Validity of Aging Treatments}

These samples were all heat treated under isothermal conditions in a laboratory furnace, thus the whole of the YSZ attained the aging temperature. It was for this reason that ceramic substrates had to be used at $1500^{\circ} \mathrm{C}$. In service, blade cooling is used and there will be a temperature gradient across the coating of $80-120^{\circ} \mathrm{C}$. Thus, in those cases where the temperature in the turbine is sufficient to cause sintering in the YSZ only the top few microns of the columns actually sinter. This will results in an enhanced erosion rate until the sintered 
layer is removed. However, continued exposure may result in further surface sintering and therefore a sustained increase in erosion rate.

The aging tests at the lower temperatures $\left(1100^{\circ} \mathrm{C}\right)$ are more representative of the temperatures the coating sees under normal service conditions, but to be truly representative of service conditions it would be necessary to age the samples with a cooling air flow across the back of the samples, thus generating a temperature gradient across the coating. This can be achieved in burner rigs and ribbon furnaces but the control of the exact temperature is difficult and not very accurate. There is definitely a benefit in testing turbine hardware that has seen service, however it is very difficult to obtain such samples for testing and the authors would welcome some engine run components for erosion testing.

\section{Conclusions}

It has been shown that thermal aging will increase the erosion rate of EB PVD TBCs when compared to virgin samples. From these preliminary studies it appears that aging at $1500^{\circ} \mathrm{C}$ for $24 \mathrm{hrs}$ increases the erosion rate by a factor of 4 due to partial sintering of the columns thus enabling crack propagation across neighbouring columns to occur resulting in a greater volume loss per impact. Aging at $1100^{\circ} \mathrm{C}$ for $100 \mathrm{hrs}$ increased the erosion rate by a factor of 2 although no evidence of column sintering could be observed.

\section{Future Work}

This work has shown that there is much about the erosion of EB PVD TBCs which still has to be researched, particularly in aged samples. Theses preliminary studies have highlighted a number of areas which need in depth investigation, namely the effect of aging and sintering 
on the properties and performance of EB PVD TBCs. A more structured and systematic investigation into these effects is currently underway the results of which will be published in the near future. This will include nano-indentation, X-ray analyses as well as erosion testing of samples in the as received condition as well as after various aging heat treatments. Since there appears to be an unexpectedly high variation in the erosion rates of the aged samples future studies will need to ensure that sufficient samples are available for erosion testing for a statistical analysis. 


\section{Reference List}

1. R.A Miller, Thermal Barrier Coatings Workshop NASA Conference Publication 3312 (1995) 17.

2. J.R Nicholls, Y Jaslier and D.S Rickerby, Materials at High Temperature, 15, (1998) 15.

3. J.R Nicholls, Y Jaslier and D.S Rickerby, Materials Science Forum, 251-254, (1997) 935.

4. R.F Handschuh, NASA Technical Paper 2406 (1984).

5. H.E Eaton and R.C Novak, Surface and Coatings Technology, 30, (1987) 41.

6. A.G Davis, D.H Boone and A.V Levy, Wear, 110, (1986) 101.

7. T Rhys-Jones and F.C Toriz, High Temperature Technology, 7, (1989) 73.

8. F.C Toriz, A.B Thakker and S.K Gupta, High Temperature Technology, 7, (1989) 1.

9. R.G Wellman and J.R Nicholls, Wear, 242, (2000) 89.

10. R.G Wellman and J.R Nicholls, Euromat 2001, Rimini Italy, 2001.

11. B.Z Janos, E Lugscheider and P Remer, Surface and Coatings Technology, 113, (1999) 278. 
Table 1: Table of the different heat treatments that the samples received for the first set of tests.

\begin{tabular}{|c|l|l|l|}
\hline & Substrate & Time hr & Temperature ${ }^{\circ} \mathrm{C}$ \\
\hline Sample 1 & $\mathrm{C} 263$ & - & - \\
\hline Sample 2 & $\mathrm{C} 263$ & - & - \\
\hline Sample 3 & $\mathrm{C} \mathrm{263}$ & 100 & 1100 \\
\hline Sample 4 & $\mathrm{C} \mathrm{263}$ & 100 & 1100 \\
\hline Sample 5 & $\mathrm{Al}_{2} \mathrm{O}_{3}$ & 24 & 1500 \\
\hline Sample 6 & $\mathrm{Al}_{2} \mathrm{O}_{3}$ & 24 & 1500 \\
\hline Sample 7 & $\mathrm{ZrO}_{2}$ & 24 & 1500 \\
\hline Sample 8 & $\mathrm{ZrO}_{2}$ & 24 & 1500 \\
\hline
\end{tabular}


Table 2: Table of the different heat treatments that the samples received for the second set of tests.

\begin{tabular}{|l|l|l|l|}
\hline & Substrate & Time hr & Temperature ${ }^{\circ} \mathrm{C}$ \\
\hline Sample 9 & $\mathrm{Al}_{2} \mathrm{O}_{3}$ & - & - \\
\hline Sample 10 & $\mathrm{Al}_{2} \mathrm{O}_{3}$ & 24 & 1500 \\
\hline Sample 11 & $\mathrm{Al}_{2} \mathrm{O}_{3}$ & 100 & 1100 \\
\hline Sample 12 & $\mathrm{ZrO}_{2}$ & 30 & 1100 \\
\hline
\end{tabular}


Table 3: Table of the radius of curvature of the samples that were aged for $24 \mathrm{hrs}$ at $1500^{\circ} \mathrm{C}$.

\begin{tabular}{|l|l|l|}
\hline Sample No & Substrate & Radius of Curvature \\
\hline Sample 5 & $\mathrm{Al}_{2} \mathrm{O}_{3}$ & $88 \mathrm{~mm} \& 71 \mathrm{~mm}$ \\
\hline Sample 6 & $\mathrm{Al}_{2} \mathrm{O}_{3}$ & $86 \mathrm{~mm} \& 66 \mathrm{~mm}$ \\
\hline Sample 7 & $\mathrm{ZrO}_{2}$ & $153 \mathrm{~mm} \& 104 \mathrm{~mm}$ \\
\hline Sample 8 & $\mathrm{ZrO}_{2}$ & $133 \mathrm{~mm} \& 111 \mathrm{~mm}$ \\
\hline
\end{tabular}


Table 4: Operating conditions of the test rig.

Temperature Range

Particle Velocities

Particle Size Range

Impact Angles

Particle Feed Rate
RT $-900^{\circ} \mathrm{C}$

$50-400 \mathrm{~m} / \mathrm{s}$ (depending on particle size)

$20-1000 \mu \mathrm{m}$

$30,45,60,75 \& 90^{\circ}$

$0.1-10 \mathrm{~g} / \mathrm{min}$ 
Table 5: Test conditions used.

\begin{tabular}{|l|l|}
\hline Erodent & Alumina \\
\hline Particle Shape & Angular \\
\hline Impact angle & $90^{\circ}$ \\
\hline Particle size & $90-125 \mu \mathrm{m}$ \\
\hline Nominal Velocity & $120 \mathrm{~m} / \mathrm{s}$ \\
\hline Feedrate & $0.52 \mathrm{~g} / \mathrm{min}$ \\
\hline Temperature & Room temperature \\
\hline
\end{tabular}


Table 6: Table of the erosion rates from the first set of samples.

\begin{tabular}{|c|c|c|c|c|}
\hline $\begin{array}{l}\text { Sample } \\
\text { No. }\end{array}$ & Condition & Substrate & $\begin{array}{l}\text { Total erosion } \\
\text { rate } \mathrm{g} / \mathrm{kg}\end{array}$ & $\begin{array}{l}\text { Steady state } \\
\text { erosion rate } \mathrm{g} / \mathrm{kg}\end{array}$ \\
\hline 1 & As Received & C263 & 10.1 & 10.1 \\
\hline 2 & As Received & C263 & 9.8 & 9.8 \\
\hline 7 & $\begin{array}{l}\text { Sintered } 1500^{\circ} \mathrm{C} \text { for } \\
24 \mathrm{hrs}\end{array}$ & $\mathrm{ZrO}_{2}$ & 30.1 & 35.8 \\
\hline 8 & $\begin{array}{l}\text { Sintered } 1500^{\circ} \mathrm{C} \text { for } \\
24 \mathrm{hrs}\end{array}$ & $\mathrm{ZrO}_{2}$ & 39.5 & 45.4 \\
\hline 4 & $\begin{array}{l}\text { Aged } 1100^{\circ} \mathrm{C} \text { for } \\
100 \mathrm{hrs}\end{array}$ & C263 & 22.5 & 22.5 \\
\hline
\end{tabular}


Table 7: Table of the erosion rates from the second set of samples.

\begin{tabular}{|l|l|l|l|}
\hline Sample No. & Condition & Total erosion rate g/kg & Steady state erosion rate g/kg \\
\hline 9 & As Received & 10.5 & 10.5 \\
\hline 12 & $1100^{\circ} \mathrm{C}$ for $30 \mathrm{hrs}$ & 11.1 & 12.2 \\
\hline 11 & $1100^{\circ} \mathrm{C}$ for $100 \mathrm{hrs}$ & 16.6 & 17.0 \\
\hline
\end{tabular}


Figure 1: Photograph showing curvature of samples heat treated at $1500^{\circ} \mathrm{C}$ for $24 \mathrm{hrs}$.

Figure 2: Schematic of the erosion rig.

Figure 3: Graph of the first set of erosion tests on thermally treated samples.

Figure 4: Graph of the second set of erosion tests on thermally treated samples.

Figure 5: Erosion rate of the TBC increasing with an increase in the sintering conditions.

Figure 6: Results of the XRD analyses, lower scan for YSZ on C263, upper scan, offset by 750cps) for YSZ deposited on alumina.

Figure 7: Two scans on the YSZ deposited on an alumina tile, lower scan before heat treatment, upper scan after $100 \mathrm{hrs}$ at $1100^{\circ} \mathrm{C}$.

Figure 8: Two scans on the YSZ deposited on an alumina tile, lower scan before heat treatment, upper scan after $24 \mathrm{hrs}$ at $1500^{\circ} \mathrm{C}$.

Figure 9: Non eroded area of TBC in the as received condition.

Figure 10: Non eroded area of TBC after ageing for $100 \mathrm{hrs}$ at $1100^{\circ} \mathrm{C}$.

Figure 11: Non eroded area of TBC after sintering for $24 \mathrm{hrs}$ at $1500^{\circ} \mathrm{C}$.

Figure 12: Cross-section of the TBCs in the as received condition (a), and after sintering for $24 \mathrm{hrs}$ at $1500^{\circ} \mathrm{C}$.

Figure 13: Cross-section of the sintered sample after erosion testing (a), and a higher magnification of the area in the rectangle (b) showing evidence of sintering occurring between the columns (indicated by arrows), following heat treatment at $1500^{\circ} \mathrm{C}$ for $24 \mathrm{hrs}$. Figure 14: Crosssection of eroded TBCs (a) aged at $1100^{\circ} \mathrm{C}$ for $100 \mathrm{hrs}$ before testing, and (b) eroded in the as received condition. 


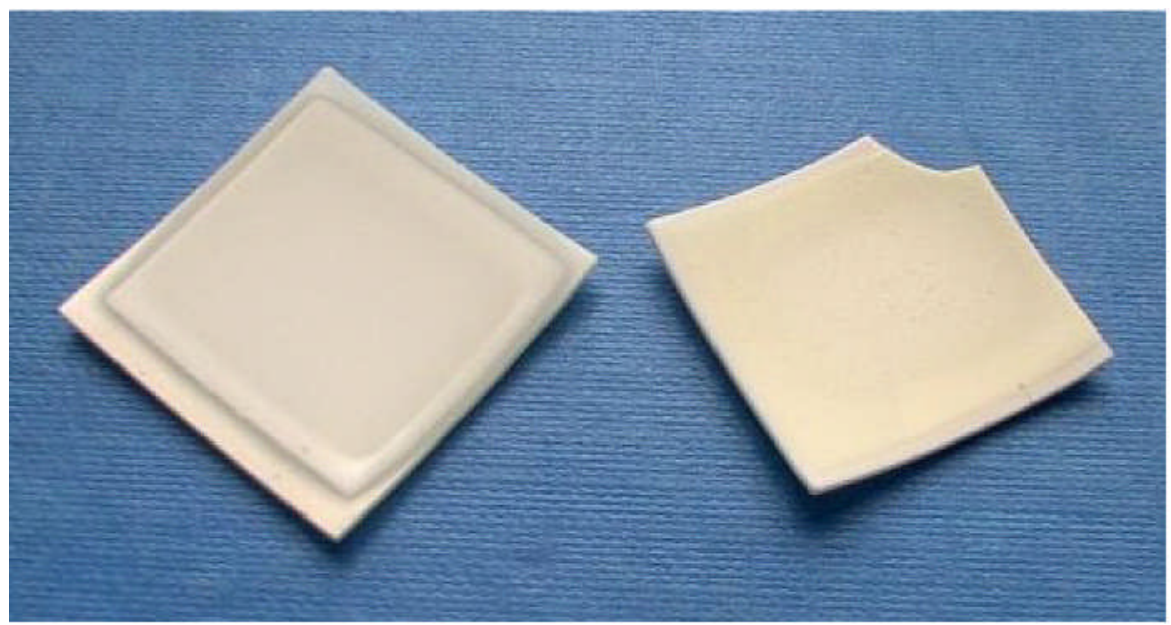

$25 \mathrm{~mm}$

Figure 1 


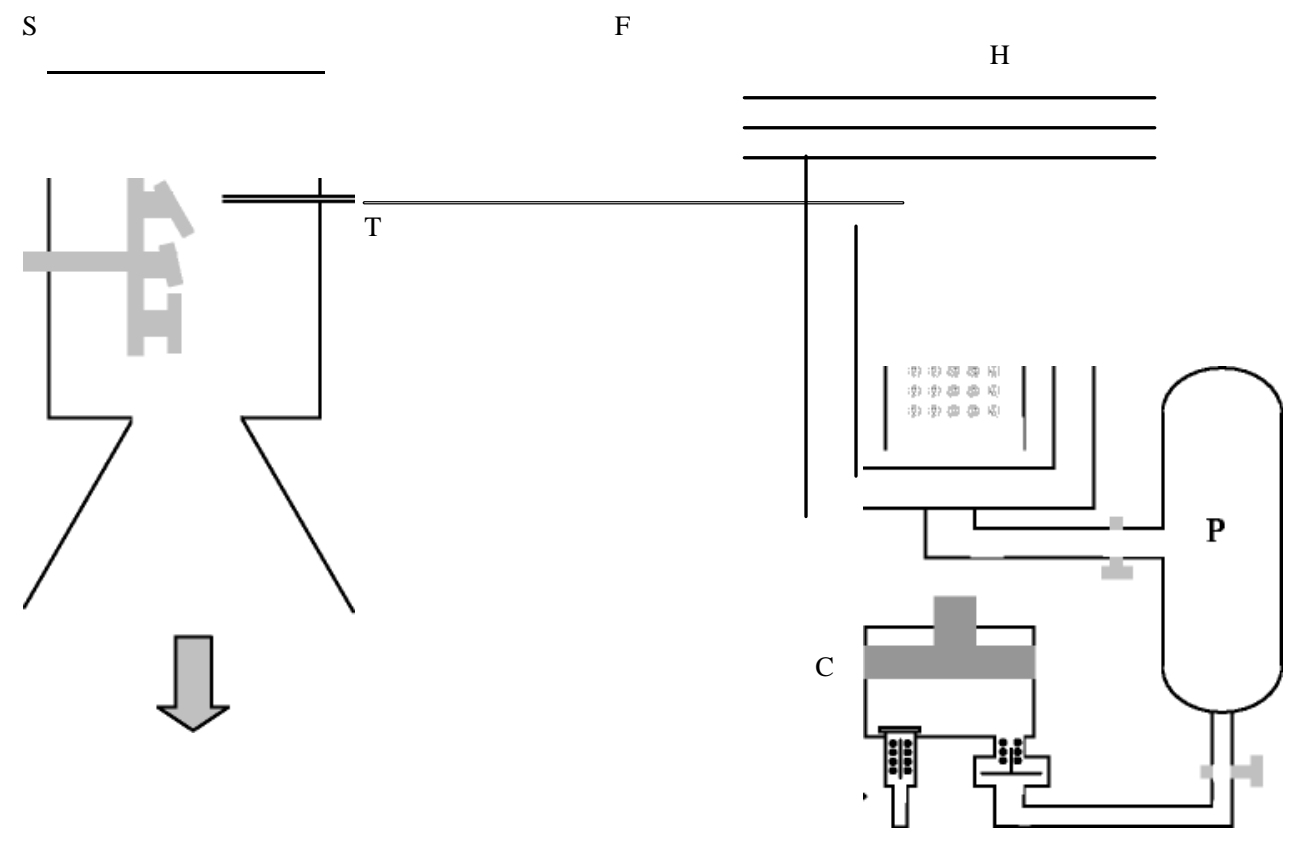

Figure 2: 


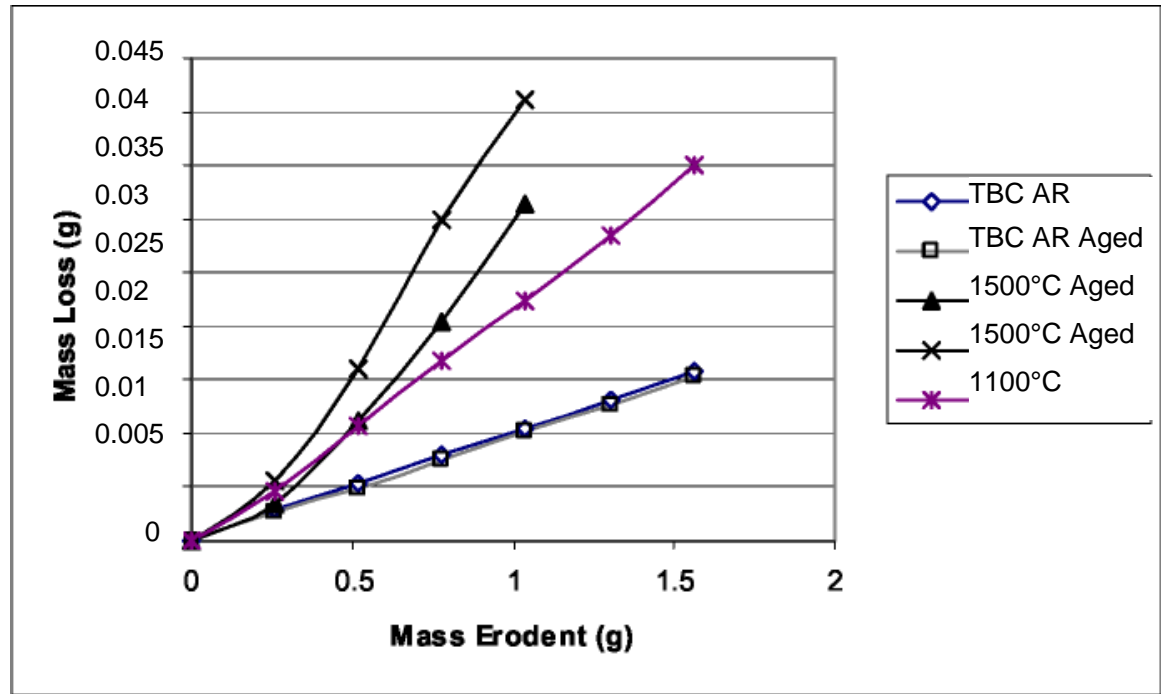

Figure 3: 


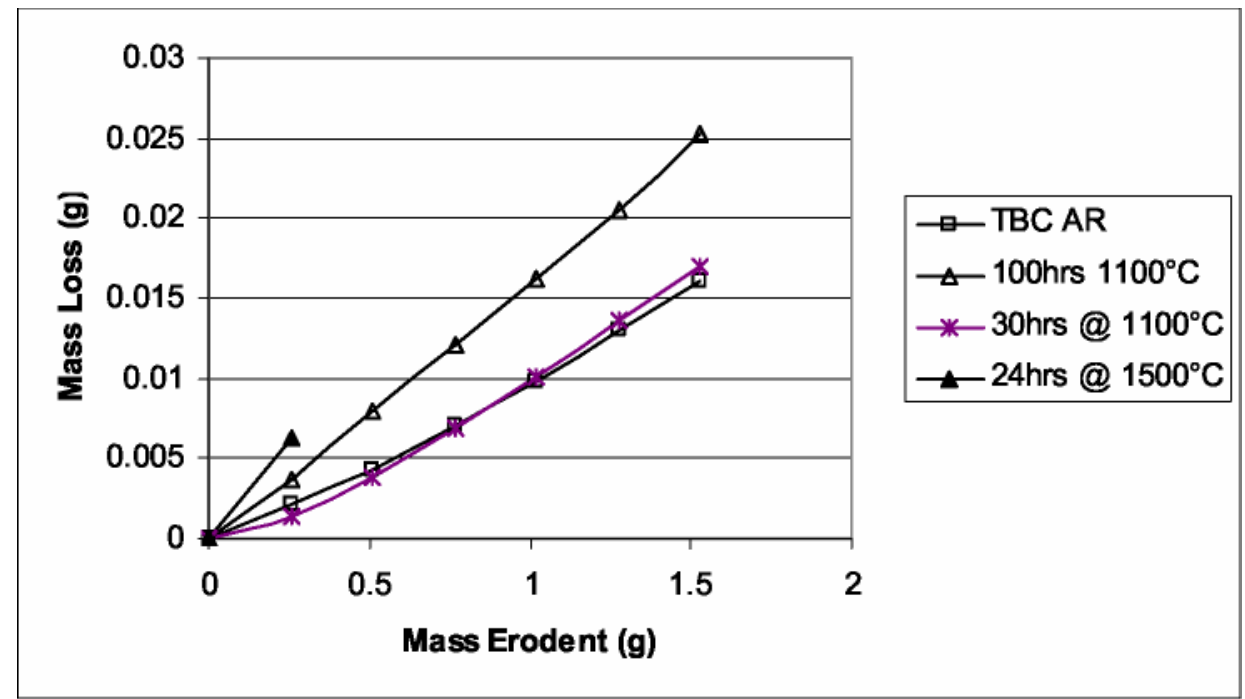

Figure 4: 


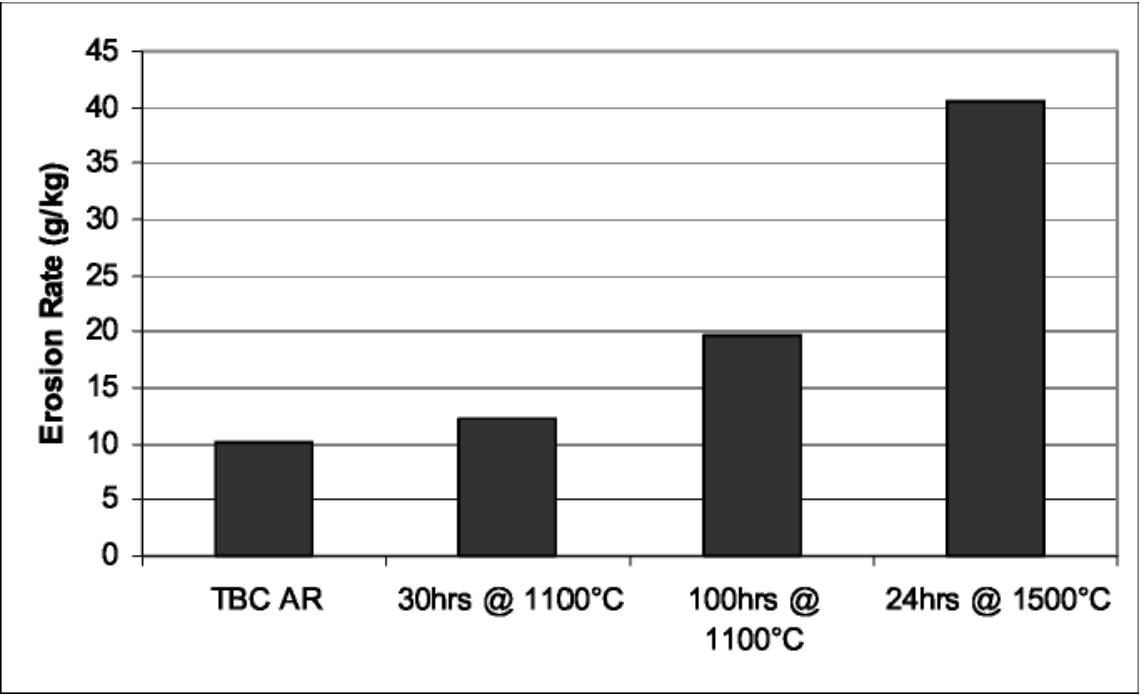

Figure5: 


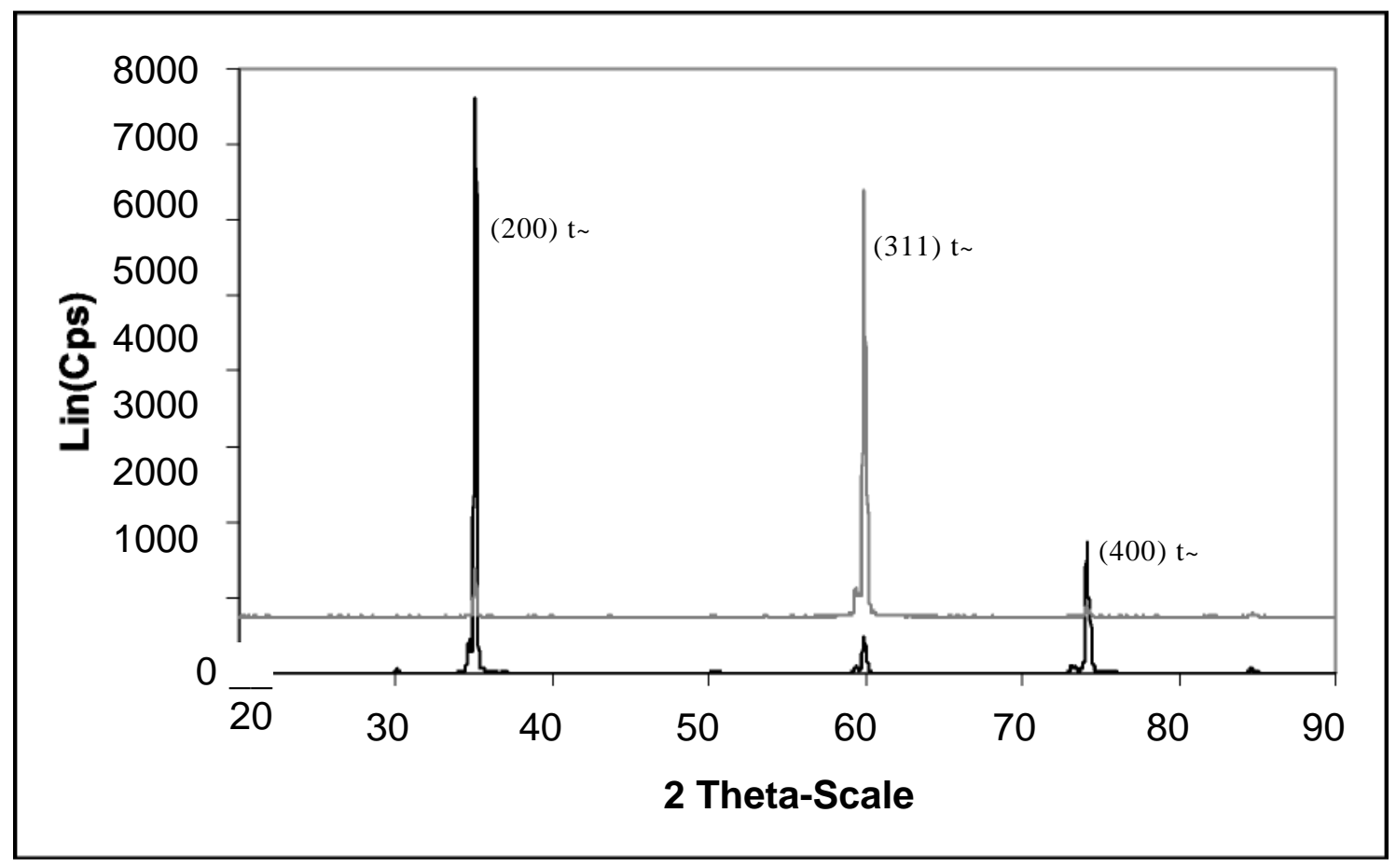

Figure 6: 


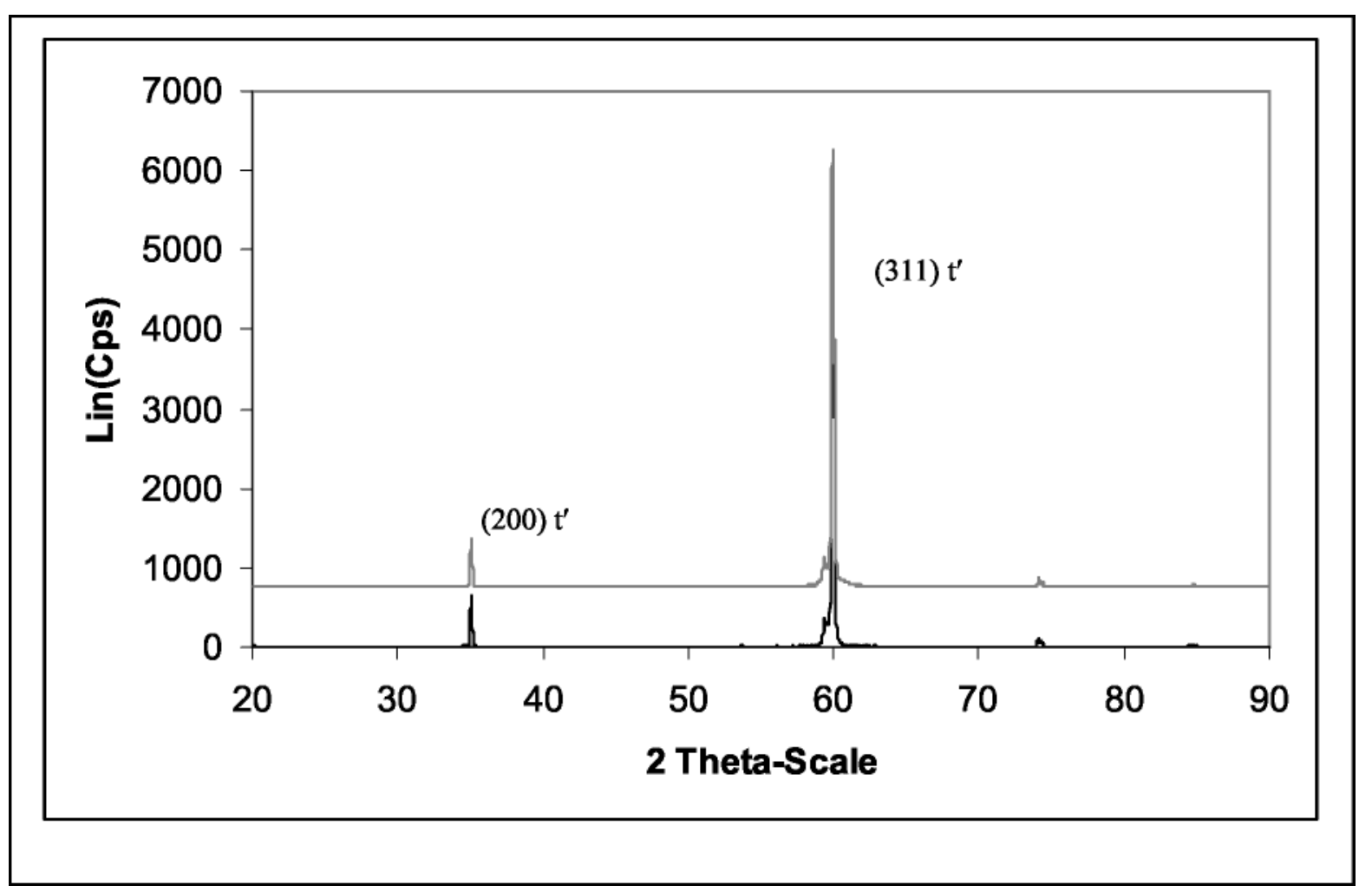

Figure 7: 


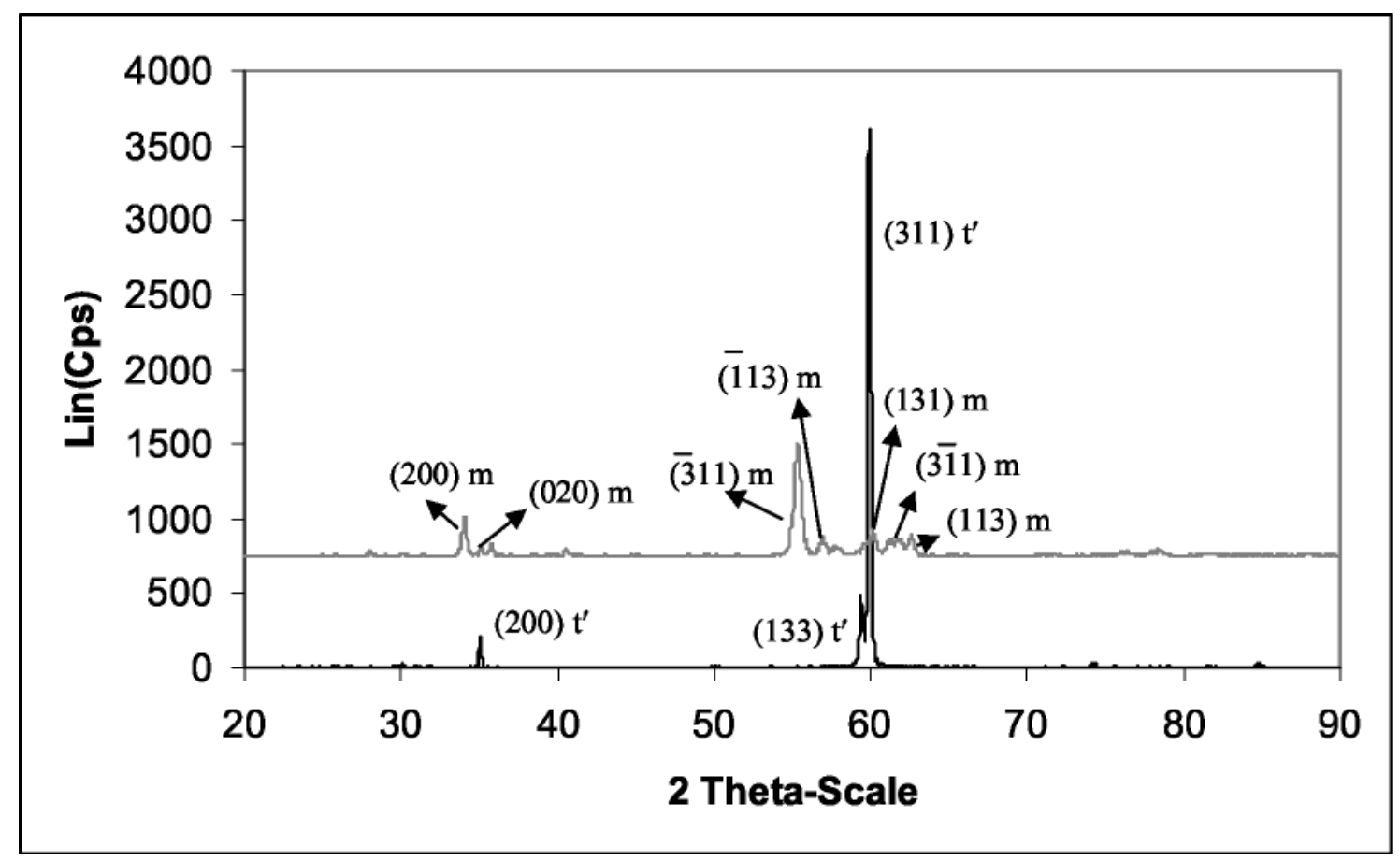

Figure 8: 


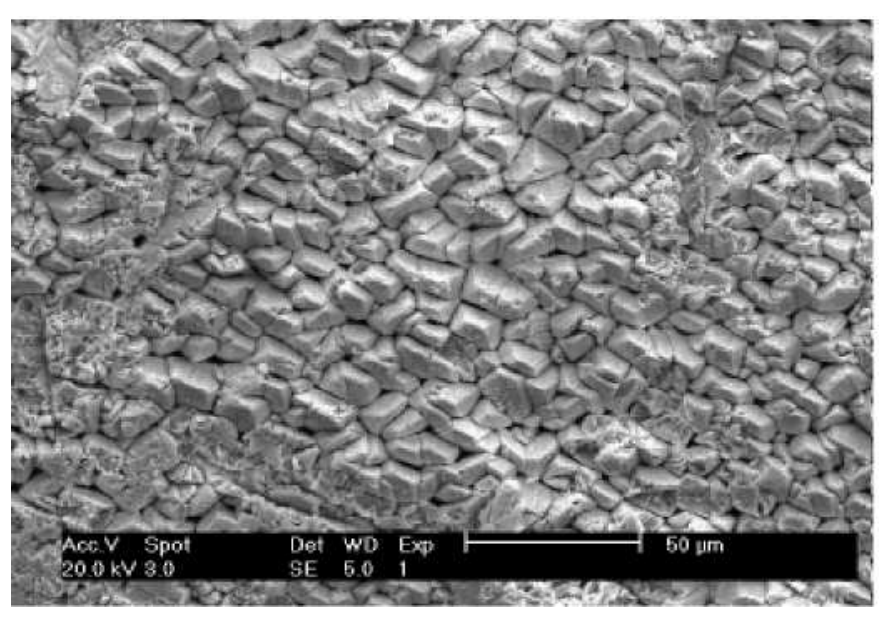

Figure 9: 


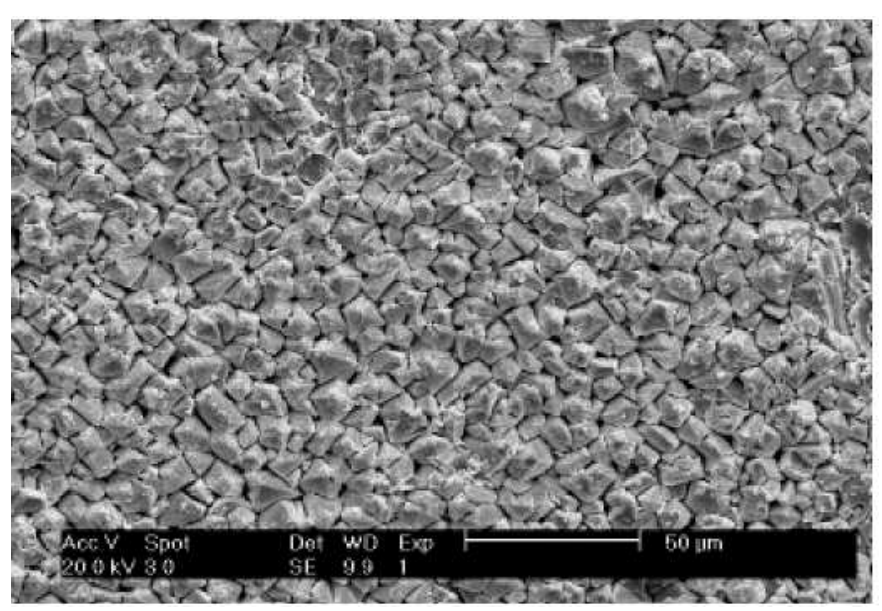

Figure 10: 


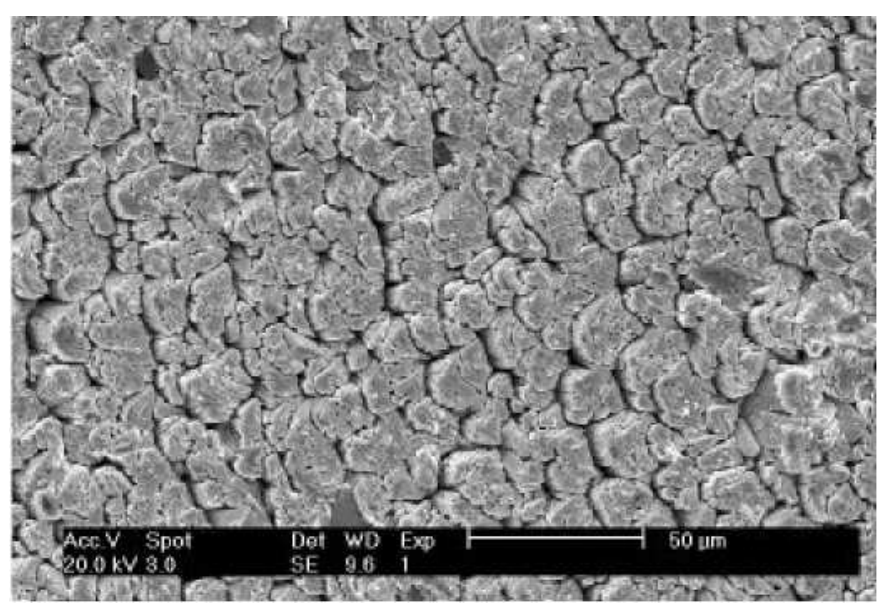

Figure 11: 

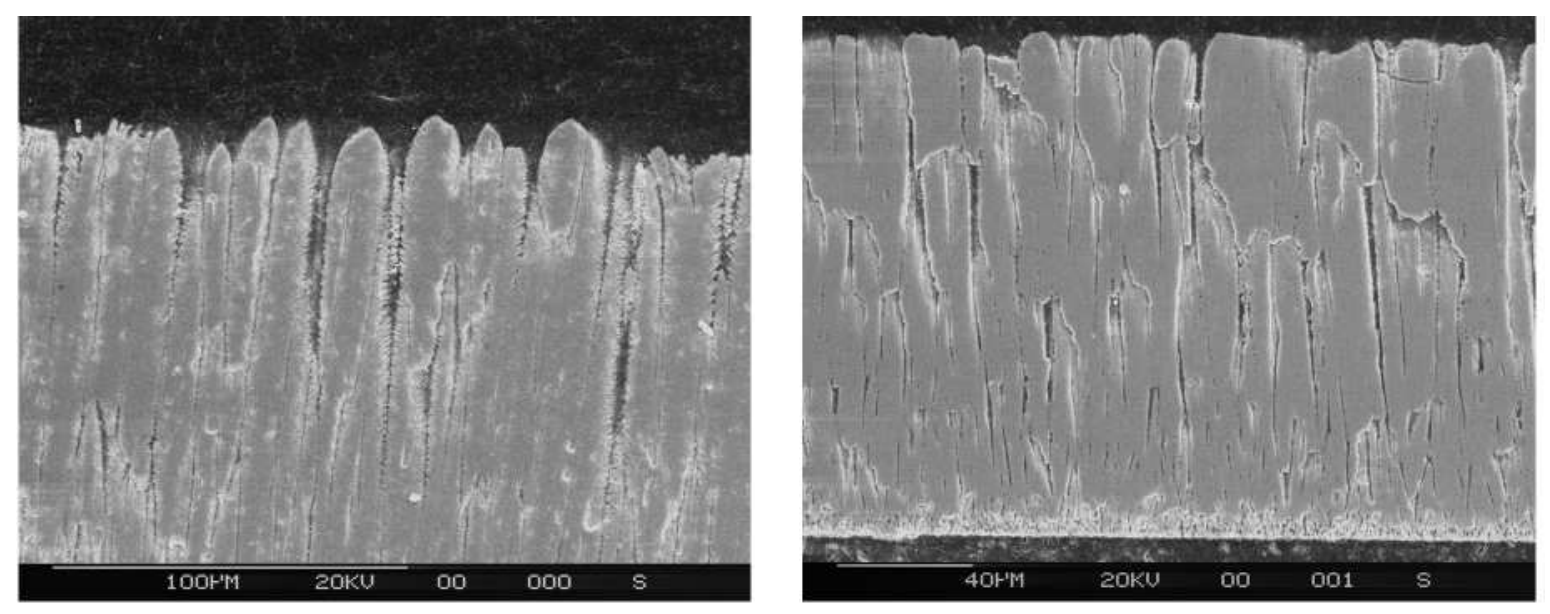

Figure 12: 
(a)

(b)

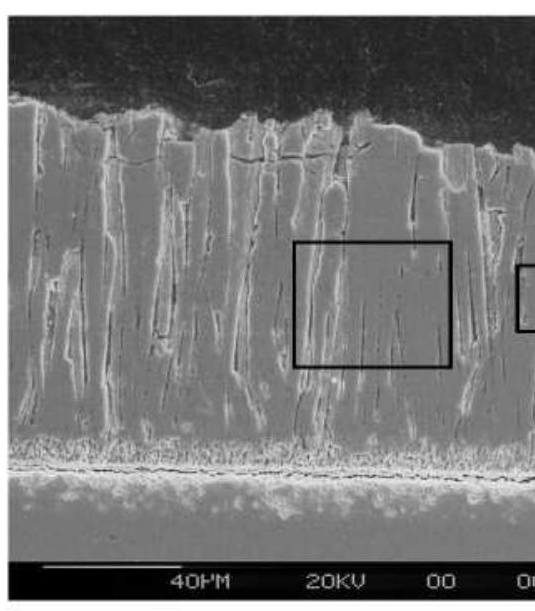

(a)

Figure 13: 

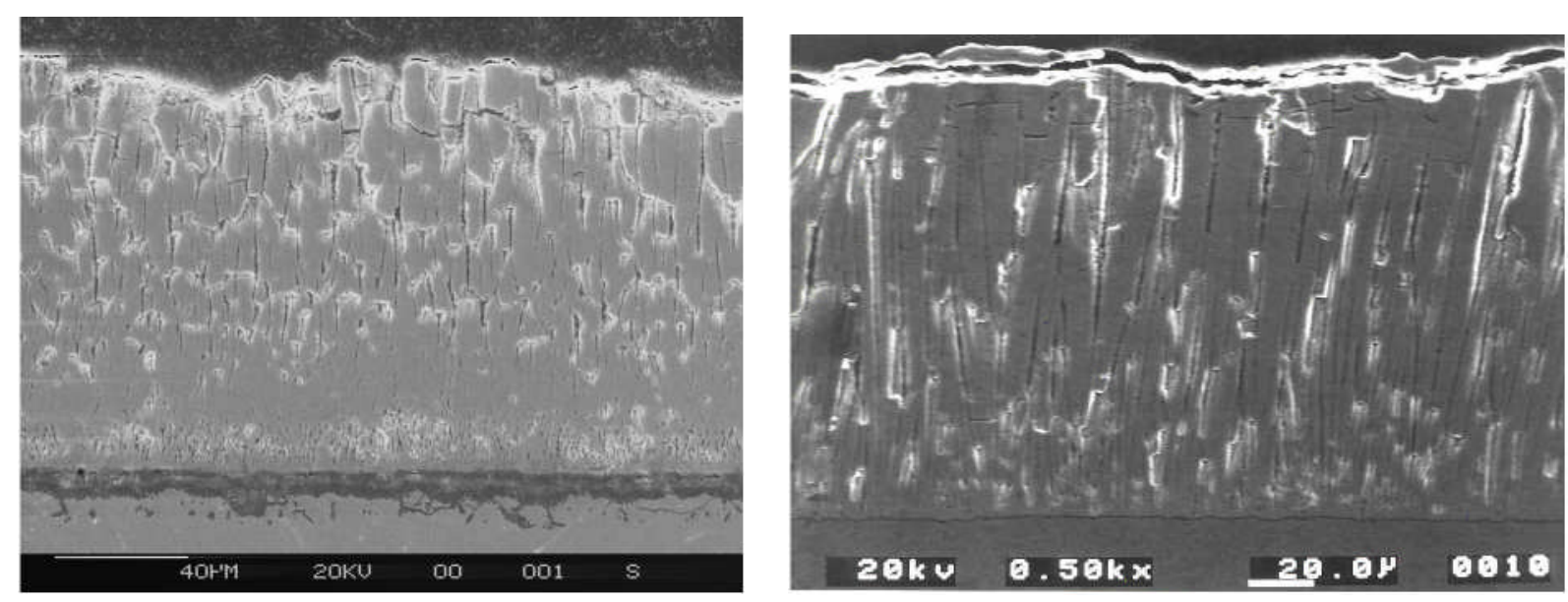

Figure 14: 